\title{
The Human Rights Act 1998: implications for the medical treatment of children and young people ${ }^{\dagger}$
}

\author{
Martin Curtice \& Tim Hawkins
}

\begin{abstract}
SUMMARY
Issues pertaining to the medical treatment of children and young people can be both complex and emotive for all involved. At such times the courts may be asked to intervene and decide. Cases invariably need to consider issues of capacity to consent and treatment under best interests. Furthermore, such cases inevitably have human rights aspects. This article analyses the diverse role of the Human Rights Act 1998 in these cases and illustrates key underlying Human Rights Act principles that can be applied in clinical practice.
\end{abstract}

\section{DECLARATION OF INTEREST}

None.

The Human Rights Act 1998 enacts most of the European Convention on Human Rights into domestic law in England and Wales. All legal cases must now consider the Act in arriving at decisions. Before and after the introduction of the Act, cases where there was dispute between parents/ guardians and healthcare professionals over the medical treatment of a child or young person have regularly been decided in the courts.

The following review of cases provides an analysis of the role of the Human Rights Act in the medical decision-making process. It concentrates on Articles 2, 3 and 8 of the Act and demonstrates their use, application and interpretation with respect to the medical treatment of children and young people, as well as core principles that can be used in clinical practice.

\section{Articles $\mathbf{2}$ and $\mathbf{3}$ of the Human Rights Act}

Articles 2 and 3 are often considered together when assessing medical treatment issues.

Article 2 has been described as 'one of the most fundamental provisions in the Convention' (McCann and others v. UK 1995: para 147). It provides that:
Everyone's right to life shall be protected by law. No one shall be deprived of his life intentionally save in the execution of a sentence of a court following his conviction of a crime for which this penalty is provided by law.

Article 2 imposes not only a negative duty not to take life intentionally or negligently, but also a positive duty to safeguard life. Under Article 2 the inherent positive obligation has two aspects, both of which prohibit the state from taking life and place on it a positive duty to 'safeguard' life (X v. United Kingdom 1978).

Article 3 is the only absolute Convention right and it states that:

No one shall be subjected to torture or to inhuman or degrading treatment or punishment.

Being an absolute right, Article 3 allows no derogations, but it can still be interpreted in various ways. Case law has elucidated various principles to be considered in its use (Box 1; for a previous review in this journal of Article 3 case law see Curtice 2008). The following points are of pertinence to medical treatment of children and young people:

- patients with and without capacity remain under the protection of Article 3

- inhuman or degrading treatment must go beyond that inevitable element of suffering or humiliation connected with a given form of legitimate treatment

- authorities are obliged to provide adequate and requisite medical care

- a treatment or intervention that is convincingly shown to be a therapeutic or medical necessity in general will not be regarded as inhuman or degrading

- domestic states have different accepted clinical practices and standards - the margin of appreciation is accepted as being very wide to reflect this. Consequently, clinical decisions that are
Martin Curtice is a consultant in old age psychiatry. He obtained a Master of Laws with Distinction in Mental Health Law in 2003 and has an interest in mental health law and the Human Rights Act. He sits on the Royal College of Psychiatrists' Special Committee on Human Rights. Tim Hawkins is a consultant in child and adolescent psychiatry. He works in a dedicated adolescent service providing out-patient, day-patient and in-patient services. His particular areas of interest include risk management in adolescents and the legal basis for treatment. Correspondence DrMartin Curtice, Consultant in Old Age Psychiatry, Hollyhill Unit, Rubery Lane, Rubery, Birmingham B45 9AY, UK.Email: mirc@ukonline.co.uk.

${ }^{\dagger}$ This article continues a series in Advances on the Human Rights Act: see Curtice M (2009) Article 8 of the Human Rights Act 1998: implications for clinical practice, 15 : 23-31; Curtice M, Sandford J (2009) Article 2 of the Human Rights Act 1998 and the treatment of prisoners, 15: 444-450. Curtice M, Sandford $J$ (2010) Article 3 of the Human Rights Act 1998 and the treatment of prisoners, 16: 105-114. Curtice M, Hawkins T (in press) The Human Rights Act 1998: Article 8 case law and implications for child and adolescent mental health services; Curtice M, Crocombe J (in press) Article 8 of the Human Rights Act 1998 and intellectual disability. Ed. 
proportional, therapeutically necessary and in keeping with accepted clinical practice are unlikely to be outside this margin.

\section{A National Health Service Trust v. D \& Others [2000]}

This case involved a 19-month-old child with severe, irreversible and worsening lung disease, which gave him a short life expectancy (he also had heart failure, hepatic and renal dysfunction with a background of severe developmental delay). The judgment opined that existing domestic principles concerning when treatment may lawfully be withheld from a seriously disabled and terminally ill child were compatible with Articles 2 and 3.

The High Court held that it would be lawful to declare that mechanical ventilation would not be in the best interests of the child and hence could be withheld. This was on the basis that further use of mechanical ventilation would inevitably lead to further periods in intensive care "bringing a death which was neither peaceful nor dignified'.

\section{BOX 1 Article 3 principles}

Capacity

Degrading treatment

Level of suffering

Margin of appreciation

Medical care

reshold of severity to engage Article 3

Therapeutic necessity
Patients with and without capacity remain under the protection of Article 3. Current jurisprudence suggests that capacity is not crucial when making decisions that may engage Article 3 as long as medical necessity is convincingly demonstrated

Treatment in which the object is to humiliate and/or debase the patient, which could adversely affect their personality. Treatment that arouses feelings of fear, anguish, inferiority and/or that shows a lack of respect for or diminishes the patient's dignity may be considered degrading

Treatment could be construed as inhuman if it causes intense physical or mental suffering in the patient

Inhuman or degrading treatment must go beyond that inevitable element of suffering or humiliation connected with a given form of legitimate treatment such as force-feeding, depot administration or electroconvulsive therapy

Domestic states have different accepted clinical practices and standards; the margin of appreciation is accepted as being very wide to reflect this. Consequently, clinical decisions that are proportional, therapeutically necessary and in keeping with accepted clinical practice are unlikely to be outside this margin

Authorities are obliged to provide adequate and requisite medical care. A delay in providing care may engage Article 3 . Good documentation in medical notes is vital both clinically and legally

III-treatment must attain a minimum level of severity; assessment of this minimum is relative. All circumstances of the case need to be considered

A treatment or intervention that is convincingly shown to be a therapeutic or medical necessity in general will not be regarded as inhuman or degrading
The judgment noted that there could be no Article 2 infringement because the treatment proposed was in the best interests of the child. It further noted that Article 3 included the right to die with dignity ( $D$ v. United Kingdom 1997).

The Court outlined four general principles applying to children and the end-of-life decisionmaking process:

- the Court's prime and paramount consideration must be for the best interests of the child, which included careful consideration of parental views. Such views could not override the Court's view of the child's best interests;

- the Court had a clear duty to respect the sanctity of human life, which imposed a strong obligation in favour of taking all steps capable of preserving life, save in exceptional circumstances;

- a course aimed at terminating life or accelerating death could not be approved (the Court was concerned only with the circumstances in which steps should not be taken to prolong life); and

- there could be no question of a court directing a doctor to provide treatment that the doctor was unwilling to give and that was contrary to that doctor's clinical judgement.

\section{An NHS Trust v. S (by his litigation friend the Official Solicitor), DG (S's father) and SG (S's mother) [2003]}

This case concerned a teenager $(\mathrm{S})$ aged 18 who had a developmental age of 5 or 6 because he had been born with the genetic condition velocardiofacial syndrome. He had severe global developmental delay and intellectual disability and was diagnosed with autism. Following an emergency admission for acute renal failure he received haemodialysis. His severe intellectual disability seriously complicated his medical treatment and he clearly lacked capacity to consent to treatment. The hospital trust brought the case to court to seek clarification about his future treatment and management of his end-stage renal failure, including the potential of an arteriovenous fistula (he had a fear of needles) and a renal transplant. The judge concurred that $\mathrm{S}$ was incapacitated in making decisions about his future medical care and all such decisions were under the doctrine of best interests. He made specific declarations as to future interventions, including the possibility that an arteriovenous fistula should not be excluded after he had settled into the adult way of life; peritoneal dialysis could be considered when haemodialysis was no longer considered effective; and the possibility of a kidney transplantation should not be excluded on nonmedical grounds. 
The judgment also made pertinent comments regarding treating such incapacitated patients in their best interests and with regard to their Article 2 Convention rights. The Court noted that the Convention requires that an incapacitated person with serious physical and mental problems should not receive "less satisfactory treatment than a person who has full capacity to understand the risks, pain and discomfort inseparable from such major surgery' and to act in any other way would be contrary to the rights of a mentally incapacitated patient both under UK domestic law and under the Convention.

When considering best interests in these cases the Court noted that the sanctity of life was a fundamental principle and there was a strong presumption in favour of a course of action that would prolong life. In the important case of Airedale NHS Trust v. Bland [1993], which considered the withdrawal of life-prolonging treatment in a man in a persistent vegetative state, the judgment opined, however, that the principle of the sanctity of life 'fundamental as it is, is not absolute... there is no absolute rule that the patient's life must be prolonged by such treatment or care, if available, regardless of the circumstances'.

The Court reiterated its inherent jurisdiction to grant declarations as to the lawfulness of the proposed medical or surgical treatment on those incapable of consenting to treatment, especially where there is disagreement between family and treating clinicians. The assessment of best interests was 'not a narrow one' and 'encompasses medical, emotional and all other welfare issues' (Re A (Male Sterilisation) 2000).

\section{Article 8 of the Human Rights Act 1998}

Article 8 is one of the most dynamically interpreted Articles because it is underpinned by the principle of proportionality. It is of particular relevance to children and young people and provides that:

1 Everyone has the right to respect for his private and family life, his home and his correspondence.

2 There shall be no interference by a public authority with the exercise of this right except such as is in accordance with the law and is necessary in a democratic society in the interests of national security, public safety or the economic well-being of the country, for the prevention of disorder or crime, for the protection of health or morals, or for the protection of the rights and freedoms of others.

Article 8 is a qualified right. Hence, if there is interference with the right in paragraph 1 then the onus is on the state to justify this within the exceptions described in paragraph 2 (for a previous review in this journal of Article 8 case law and principles see Curtice 2009a). Article 8 is often considered alongside Article 3 in treatment issues (Curtice 2009b).

\section{Re C \& F (Children) [2003]}

This judgment involved two similar (but unconnected) applications listed together, relating to two girls aged 4 and 10. The girls had not been inoculated nor received any form of immunisation (although strongly recommended by doctors and widely taken up, it was not a legal requirement). The fathers both considered that there was convincing medical evidence for their daughters to receive a range of immunisations appropriate to their age in their best interests. Both of the mothers opposed this and considered that immunisation presented unacceptable risks.

The Court observed that where there is such a dispute between parents that they are unable to resolve, either of them may apply to the Court for a specific issue order pursuant to Section 8 of the Children Act 1989 (Residence, contact and other orders with respect to children) to determine the issue. The fathers so applied. (This was believed to be the first time that the question of immunisation had arisen for determination - other disputes involving medical treatment, choice of schools and change of name arise quite frequently.)

Under Section 1 of the Children Act (Welfare of the child), the Court had to determine whether immunisation was in each of the girls' best interests because their welfare was the Court's paramount consideration. If it was in their best interests, the Court needed next to consider whether there were good reasons why that declaration should not be made (such reasons might arise if making the declaration would so affect the mother that her ability to care for the child would be impaired, or it would be otherwise adverse to the child's best interests).

In considering Article 8, the Court noted that it may interfere with the competing rights of both parents and children where to do so was to protect the health of a child. The Court further opined that the parent with whom a child is living, whether mother or father, does not have greater rights than an absent parent who is entitled to be consulted on major decision in the child's life (each of the girls lived alone with their respective mother).

The Court decided that under Article 8, it was legitimate for the court to interfere with the rights of both parents and children where the purpose of doing so was to protect the health of a child. 
On the medical evidence the Court ruled that immunisation was in the children's best interests, even without the consent of their mothers.

\section{Sentges v. The Netherlands (2003)}

The Dutch health authorities and insurance companies refused to fund an expensive robotic arm for a young man with Duchenne muscular dystrophy, which would have enhanced his autonomy and enabled him to live at home for longer. The Court noted that Article 8 does not merely compel the state to abstain from interference with a person's private life (a negative obligation) but may impose positive obligations inherent in effective respect for private or family life (i.e. adoption of measures designed to secure respect for private life).

The applicant submitted that the refusal to be provided with a robotic arm infringed his Article 8 rights. The Court rejected the complaint and noted that regard must be had to the fair balance that must be struck between the competing interests of the individual and those of the community as a whole. The Court also noted that the already wide margin of appreciation was even wider when the issues involve assessment of priorities in the context of the allocation of limited state resources - i.e. there is no guarantee of a specific level of care of medical treatment and lack of resources may influence this.

\section{Glass v. United Kingdom (2004)}

The applicants in this case were a mother and son. The son was severely disabled and needed 24-hour care. His mother opposed the use of diamorphine to alleviate her son's distress when he became critically ill following an operation. It was considered that resuscitation would not be in the son's best interests. The mother asked to take her son home if he was dying but was advised that she would be arrested should she attempt to remove him. The mother believed that the dose of diamorphine was excessive; family members believed that the doctors were carrying out covert euthanasia. They attempted to prevent the doctors from entering his room and a fight broke out. The mother successfully resuscitated her son while the fight ensued and he subsequently improved such that he was discharged.

The mother alleged that both her own Article 8 rights and those of her son had been breached. The European Court agreed that the Article 8 rights of the son had been breached. The decision to administer diamorphine to the son in defiance of his mother's objections amounted to an interference with his right to respect for his private life and in particular his right to physical integrity under Article 8(1). Under Article 8(2), the interference was in accordance with the law, the action taken by the hospital staff pursued a legitimate aim and it was not the doctors' intention to hasten the son's death. In deciding whether the interference was necessary in a democratic society, the Court was not satisfied as to why the hospital failed to seek High Court intervention (the onus being on them to initiate such a procedure), especially as the prognosis was deemed to be poor and they knew that their proposed treatment would not meet with the mother's agreement. Furthermore, the Court was not convinced that the need to provide diamorphine constituted such an emergency that High Court involvement could not have been sought at that stage (especially because the best-interests procedure can be invoked at short notice).

\section{$R$ (on the application of Sue Axon) v. The Secretary of State for Health and The Family Planning Association (Intervenor) [2006]}

The claimant (a parent) applied for judicial review of a Department of Health document (2004) providing guidance to health professionals on giving advice and treatment to people under the age of 16 on sexual matters.

The guidancestated that the duty of confidentiality owed to a young person was the same as that owed to any other person. This was not absolute and could be overridden in exceptional circumstances where there was a risk to the person's health, safety or welfare. It provided that a health professional could give advice and treatment on sexual matters, without parental knowledge or consent, provided that the young person understood the advice and its implications. Any advice or treatment would be in their best interests. The guidance also recommended that doctors follow the criteria set out by Lord Fraser in Gillick v. West Norfolk and Wisbech Area Health Authority (1986), i.e. the Gillick competency test.

Among several concerns, the parent in particular contended that the guidance was unlawful and health professionals should not be entitled to provide advice and treatment on sexual matters without the parents' knowledge. Furthermore, the guidance failed to discharge the state's positive obligation to give practical and effective protection to her rights for a family life under Article 8. The seminal (pre-Human Rights Act) Gillick decision was reconsidered in depth with regard to Article 8. 
The judgment opined that it was important to recognise that, on the whole, a parent was the best person for guiding a young person under the age of 16 and that parents had a duty to protect their children. However, although secrecy was destructive to family life, those factors did not override the duty of confidentiality owed to the child. The judgment emphasised the principle of respecting the confidentiality of health information ( $Z$ v. Finland 1997; MS v. Sweden 1999) and that a duty of confidentiality was owed to a young person by healthcare professionals.

The judgment ruled that the guidance was still lawful and made it clear that the initial duty of a health professional was to seek to persuade the young person to inform his or her parents and that Gillick guidelines were to be followed. Any treatment and advice must be in the best interests of the young person. It concluded that there was no infringement of the Article 8(1) rights of a young person's parents if a health professional were permitted to withhold information about a young person relating to advice or treatment on sexual matters.

Even if the guidance did interfere with parents' rights under Article 8(1), the judgment explained at paragraph 59 that interference would be justified under Article 8(2) as being 'necessaryin a democratic society for the protection of health... or the rights of others'. First, there was clear evidence that confidentiality increased the use of contraceptive and abortion services for those under the age of 16 ; second would be the 'disturbing consequences' of young people being deterred from obtaining sexual advice and treatment; and third, the guidance did not interfere with parental Article 8 rights because a child's Article 8 rights override similar rights of a parent (Hendricks v. Netherlands 1992; Yousef v. Netherlands 2003). Thus, the Gillick principles were unaffected by Article 8 and continued to be valid and applicable.

The judgment specifically assessed the issue of proportionality, a central principle in the application of Article 8. It applied a test of proportionality from previous jurisprudence (de Freitas v. Permanent Secretary of Ministry of Agriculture 1999, at paragraph 80):

(i) the legislative objective is sufficiently important to justify limiting a fundamental right [e.g. the objectives of reducing pregnancies and curing STDs in young people; the importance of confidentiality for young people seeking advice on sexual matters];

(ii) the measures designed to meet the legislative objectives are rationally connected to it [i.e. Lord Fraser's Guidelines and the 2004
Guidance were designed to meet these objectives as well as being rationally connected to it]; and

(iii) the means used to impair the right or freedom are no more than is necessary to accomplish the objective [i.e. the terms of Lord Fraser's Guidelines and of the 2004 Guidance go no further than are necessary to achieve the objectives].

\section{Re OT (A Child) [2009]}

This Court of Appeal judgment considered Article 8 in refusing permission for parents to appeal previous orders made by the High Court (Re OT 2009) as to the end-of-life care of their 10-month-old child. The previous order had stated, notwithstanding the refusal of the parents to consent, that it would be lawful and in OT's best interests for the hospital to withdraw and withhold treatment in the knowledge that this would lead to OT's death soon after.

The child had a rare mitochondrial condition of genetic origin. He was completely dependant upon ventilation. A stroke had led to permanent brain-stem damage; he was unable to suck or swallow and needed nasogastric tube feeding. He consequently needed regular oropharyngeal and tracheal suctioning, which evidently caused not only discomfort but great pain. Whatever future interventions, he would probably die before reaching the age of three.

The trust contended that OT's death was inevitable and that any prolongation of interventions that had been used to keep him alive and improve his condition had proved unsuccessful and had actually caused 'gratuitous pain' (pain without countervailing benefit). The hospital contended that the time had come to be allowed to discontinue treatment, knowing that this would result in OT's immediate death. The parents vehemently opposed this.

The parents contended that their refused application for an adjournment by the High Court was a procedural flaw that infringed OT's Article 8 right to private and family life. They also contended that the hospital's delay in taking legal proceedings until after a deterioration in OT's condition was 'unacceptably, and in terms of human rights unlawfully, late' and should have been taken earlier when it was clear that the hospital's views about future treatment would collide with parental views.

The Court was reminded of 'the timing question', which needed to be 'fact and case specific', in the similar case of Portsmouth Hospitals NHS Trust v. Wyatt [2005], which opined at paragraph 98 that: 
there was a balance to be struck between: (a) applying in advance of a crisis when the exact medical evidence may be subject to some revision; and (b) waiting for a time which is nearer the crisis but with all the practical problems of a rushed hearing.

The Court of Appeal ruled that the parents were not allowed to appeal the previous decisions of the High Court to refuse their adjournment application and to proceed with a determination of best interests of their child.

\section{Intellectual milestones and the assessment of best interests}

The case of An NHS Trust v. MB [2006] did not specifically address Human Rights Act issues, but clearly pertained to the 'sanctity of life' and 'human' issues in the consideration of end-of-life care for a

BOX 2 Intellectual milestones for the best-interests treatment of children

- There is a well-established procedure whereby in disputed cases a hospital or National Health Service trust can apply to the High Court for a declaration. Such cases concern, in its widest sense 'the upbringing of a child'; accordingly, section 1 of the Children Act 1989 provides the statutory test that 'the child's welfare shall be the court's paramount consideration

- In disputes arising between treating doctors and the parents, where the Court has been asked to make a decision, it is the role and duty of the Court to do so and to exercise its own independent and objective judgment. The right and power of the Court to do so only arises because the patient, a child, lacks the capacity to make a decision for himself

- The ruling judge is not deciding what decision they might make for themselves if they were, hypothetically, in the situation of the patient, nor for a child of their own if in that situation, nor whether the respective decisions of the doctors on the one hand or the parents on the other are reasonable decisions. The matter must be decided by the application of an objective approach or test. That test is the best interests of the patient

- 'Best interests' is used in the widest sense and includes every kind of consideration capable of affecting the decision. These include, non-exhaustively, medical, emotional, sensory (pleasure, pain and suffering) and instinctive (the human instinct to survive) considerations. It is impossible to weigh such considerations mathematically, but the Court must do its best to balance all of the conflicting considerations in a particular case and see where the final balance of the best interests lies

- Considerable weight - a very strong presumption - must be attached to the prolongation of life because the individual human instinct and desire to survive is strong and must be presumed to be strong in the patient. But it is not absolute, nor necessarily decisive, and may be outweighed if the pleasures and the quality of life are sufficiently small and the pain and suffering or other burdens of living are sufficiently great

- All of these cases are very fact-specific, i.e. they depend entirely on the facts of the individual case

- The views and opinions of both the doctors and the parents must be carefully considered. Where the parents spend a great deal of time with their child, their views may have particular value because they know well the patient and how he reacts, although the Court needs to be mindful that the views of any parents may understandably be influenced by their own emotion or sentiment

- The parents' wishes, however understandable in human terms, are wholly irrelevant to consideration of the objective best interests of the child, save to the extent in any given case that they may illuminate the quality and value to the child of the child-parent relationship severely ill child. The case involved an 18-month-old child who had spent all but the first 7 weeks of his life in hospital. He had spinal muscular atrophy, a progressive and degenerative neurological disorder, and needed assisted ventilation. The issue for the Court was to choose from five future care options while carefully balancing the views of doctors and parents. The trust and doctors sought that the endotracheal tube would be gently withdrawn at a time and place that was carefully planned and agreed. Appropriate sedation would be given to dull pain and distress but not to itself cause death. The child would die rapidly but peacefully, disconnected from all equipment, and in the arms of his parents if they wished. The parents wished for long-term ventilation.

The judgment noted previous legal decisions in which approval had been given for the withdrawal of life support from brain-dead or severely braindamaged children, resulting in their immediate death ( $\operatorname{Re} C$ (A baby) 1996). There had also been decisions in which advance approval had been given to withhold forms of treatment or life support if later indicated ( Wyatt $\&$ Anor v. Portsmouth Hospital NHS \& Anor 2005). This case, however, was the first to be asked to decide, against the will of the child's parents, that life support be withdrawn or discontinued, with the inevitable and immediate death of a conscious child with sensory awareness and assumed normal cognition and no reliable evidence of any significant brain damage. The choice was between the central issue of withdrawing ventilation and an early and dignified death against prolongation of life. The judge was not persuaded that it was in the best interests of the child to discontinue ventilation, and felt that it was in his best interests to continue ventilation along with nursing and medical care. The judge made declarations as to the withholding of certain procedures (such as cardiopulmonary resuscitation, administration of intravenous antibiotics or blood sampling) if the child was naturally nearing death. In arriving at his decision he drew on previous jurisprudence that had elucidated well-established intellectual milestones and a legal and ethical framework for the best-interests treatment of children and young people (Box 2).

\section{Discussion}

The above cases illustrate the diverse way in which certain Human Rights Act Articles can be engaged with regard to treatment issues. They also demonstrate key underlying principles of the Act, such as proportionality and margin of appreciation. Article 2 will always be pertinent particularly for end-of-life treatment issues. Article 3 has also 
been important in cases of child abuse where it was found to be violated ( $Z$ and others $v$. United Kingdom 2001; E and others v. United Kingdom 2002). Article 8 will also continue to be important and at times pivotal in treatment issues pertaining to children and young people.

The issue of the Human Rights Act and human rights for children and young people and their treatment has gained further prominence and importance from other authorities. Whereas it is not part of UK law, the UN Convention on the Rights of the Child can be referred to, and is increasingly being used, in court and other proceedings, for example $R$ (on the application of Sue Axon) [2006]. Key principles of this Convention pertinent to treatment issues include that:

- all of the rights guaranteed by the Convention must be available to all children without discrimination of any kind (Article 2)

- the best interests of the child must be a primary consideration in all actions concerning children (Article 3)

- all children have the right to life, survival and development (Article 6)

- governments should do everything possible to protect the right of every child and young person to a name and nationality and to family life (Article 8)

- children's views must be considered and taken into account in all matters affecting them (Article 12).

The issue of treatment and best interests of children and young people has been brought into stark relief for clinicians with the 2007 amendments to the Mental Health Act and the new concept of the 'zone of parental control' outlined in the Code of Practice (Department of Health 2008). The zone encapsulates the increasing autonomy of competent young people amid the decision-making rights of competent parents. The zone derives largely from European Court of Human Rights case law. It is probable that decisions relating to this new concept will be subject to legal challenges in the courts. Both the General Medical Council (2010) and the Royal College of Paediatrics and Child Health (2004) have provided guidance for end-of-life care that often involves withholding or withdrawing life-sustaining treatment. In both publications the importance of the Human Rights Act is emphasised in underpinning such approaches. Such publications are not authoritative as to law, but they may be drawn on and given significant credence by courts, as was the Royal College of Paediatrics and Child Health guidance on withholding or withdrawing life-sustaining treatment of children in An NHS Trust v. MB [2006].

\section{References}

Curtice M (2008) Article 3 of the Human Rights Act 1998: implications for clinical practice. Advances in Psychiatric Treatment 14: 389-97.

Curtice M (2009a) Article 8 of the Human Rights Act 1998: Implications for clinical practice. Advances in Psychiatric Treatment 15: 23-31.

Curtice M (2009b) Medical treatment under Part IV of the Mental Health Act 1983 and the Human Rights Act 1998: review of Article 3 and 8 case law. Psychiatric Bulletin 33: 111-5.

Department of Health (2004) Best Practice Guidance for Doctors and Other Health Professionals on the Provision of Advice and Treatment to Young People Under 16 on Contraception, Sexual and Reproductive Health (Gateway Reference Number 3382). Department of Health.

Department of Health (2008) Code of Practice: Mental Health Act 1983. TSO (The Stationery Office).

General Medical Council (2010) Treatment and Care towards the End of Life: Good Practice in Decision-Making. GMC (http://www.gmc-uk.org/ static/documents/content/End_of_life.pdf).

Royal College of Paediatrics and Child Health (2004) Withholding or Withdrawing Life Sustaining Treatment in Children. A Framework for Practice (2nd edn). Royal College of Paediatrics and Child Health.

Airedale NHS Trust v. Bland [1993] AC 789, [1993] 2 WLR 316, [1993] 1 All ER 821, [1992] UKHL 5.

A National Health Service Trust v. D \& Others [2000] 2 FLR 677; (2000) 55 BMLR 19; [2000] Lloyd's Rep Med 412.

An NHS Trust v. S (by his litigation friend the Official Solicitor), DG (S's father) and SG (S's mother) [2003] EWHC 365 Fam.

An NHS Trust v. MB [2006] EWHC 507 (Fam).

D v. United Kingdom [1997] 24 EHRR 423.

de Freitas v. Permanent Secretary of Ministry of Agriculture [1999] 1 AC 69.

E and others v. United Kingdom (2002) European Court of Human Rights (Merits) Application no. 33218/96, 26th November.

Gillick v. West Norfolk and Wisbech Area Health Authority (1986) AC 112.

Glass v. United Kingdom (2004) European Court of Human Rights (Merits) Application no. 61827/00, 9th March.

Hendricks v. Netherlands (1992) EHRR 223

McCann and others v. UK (1995) ECHR Application no. 18984/91, 27th September 1995.

MS v. Sweden [1999] 28 EHRR 313

Portsmouth Hospitals NHS Trust v. Wyatt [2005] 1 WLR 3995

$R$ (on the application of Sue Axon) v. The Secretary of State for Health and The Family Planning Association (Intervenor) [2006] EWHC 37 (Admin).

Re A (Male Sterilisation) [2000] 1 FLR 549.

$\operatorname{Re} C$ (A baby) [1996] 2 FLR 43.

Re C \& F (Children)[2003] EWHC 1376 Fam.

Re OT (2009) EWHC 633 (Fam).

Re OT (A Child) [2009] EWCA Civ 409

Sentges v. The Netherlands (2003) European Court of Human Rights, Application no. 27677/02, 8th July 2003.

Wyatt \& Anor v. Portsmouth Hospital NHS \& Anor [2005] EWCA Civ 1181

X v. United Kingdom (1978) 14 DR 31.

Yousef v. Netherlands (2003) 36 EHRR 345

Z v. Finland (1997) European Court of Human Rights (Merits) Application no. 22009/93, 2nd February.

$Z$ and others v. United Kingdom (2001) European Court of Human Rights (Merits) Application no. 29392/95, 10th May.
MCO answers

$1 \mathrm{c} \quad 2 \mathrm{c} \quad 3 \mathrm{a} \quad 4 \mathrm{~d} \quad 5 \mathrm{~d}$ 
MCOs

Select the single best option for each question stem

1 With regard to Article 3 case law:

a only patients with capacity remain under the protection of Article 3

b only patients without capacity remain under the protection of Article 3

c a treatment or intervention that is convincingly shown to be a therapeutic or medical necessity in general will not be regarded as inhuman or degrading

d inhuman or degrading treatment does not need to go beyond that inevitable element of suffering or humiliation connected with a given form of legitimate treatment

e authorities are not obliged to provide adequate and requisite medical care.

2 Regarding the court's role in end-of-life decision-making processes for children:

a parental views will override the views of the court

b the court's prime and paramount consideration must be for the best interests of the child, which does not include careful consideration of parental views

c the court has a clear duty to respect the sanctity of human life, which imposes a strong obligation in favour of taking all steps capable of preserving life, save in exceptional circumstances

d courts can approve a course of treatment that is aimed at terminating life or accelerating death

e courts can direct a doctor to provide treatment that the doctor is unwilling to give and that is contrary to that doctor's clinical judgement.

3 With regard to the best-interests treatment of children:

a in disputes arising between treating doctors and the parents, where the court has been asked to make a decision, it is the role and duty of the court to do so and to exercise its own independent and objective judgment

b the right and power of the court to make decisions in disputes between parents and treating doctors arises because the parents lack capacity to make the decision

c an absolute presumption will be attached to the prolongation of life because the individual human instinct and desire to survive is strong and must be presumed to be strong in the patient d there is a well-established procedure whereby in disputed cases a hospital or National Health Service trust can apply to the magistrates' court for a declaration

e a ruling court judge decides what decision they might make for themselves, or a child of their own, if they were, hypothetically, in the situation of the patient.

4 Considerations when assessing best interests for treatment decisions do not include:

a pain

$\mathrm{b}$ emotional issues

c suffering

d financial issues

e pleasure.

5 The following is correct:

a Article 2 imposes only a negative duty not to take life

b Article 2 imposes only a positive duty to safeguard life

c Article 3is a qualified right

d Article 3 is an absolute right

e to engage Article 3 , ill-treatment does not need to attain a minimum level of severity.

\section{IN OTHER} WORDS

\section{From The History of Rasselas, Prince of Abyssinia, by Samuel Johnson}

\section{Selected by Femi Oyebode}

Samuel Johnson (1709-1784) was a poet, essayist, literary critic, editor and lexicographer. He compiled the first dictionary of the English language, published 1755. This extract is from The History of Rasselas, Prince of Abyssinia, published in 1759 .

doi: 10.1192/apt.16.6.420
'About ten years ago,' said he, 'my daily observations of the changes of the sky led me to consider whether, if I had the power of the seasons, I could confer greater plenty upon the inhabitants of the earth. This contemplation fastened on my mind, and I sat days and nights in imaginary dominion, pouring upon this country and that the showers of fertility, and seconding every fall of rain with a due proportion of sunshine. I had yet only the will to do good, and did not imagine that I should ever have the power.

'One day as I was looking on the fields withering with heat, I felt in my mind a sudden wish that I could send rain on the southern mountains, and raise the Nile to an inundation. In the hurry of my imagination I commanded rain to fall; and by comparing the time of my command with that of the inundation, I found that the clouds had listened to my lips.'

'Might not some other cause,' said I, 'produce this concurrence? The Nile does not always rise on the same day.'

'Do not believe,' said he, with impatience, 'that such objections could escape me. I reasoned long against my own conviction, and laboured against truth with the utmost obstinacy. I sometimes suspected myself of madness, and should not have dared to impart this secret but to a man like you, capable of distinguishing the wonderful from the impossible, and the incredible from the false.' 